hydrate diet, reduced physical activity, and obesity may be the important factors implicated. And all these factors seem to operate in the Nauruan population. ${ }^{8}$

This work was supported in part by a grant from the National Health and Medical Research Council of Australia. We thank the government of the Republic of Nauru for allowing the study to proceed, and Miss Roma Swan for typing the manuscript.

\section{References}

${ }^{1}$ Prior, I A M, et al, Lancet, 1966, 1, 333

2 West, K M, Diabetes, 1974, 23, 841.

${ }^{3}$ Zimmet, P, et al, Diabetologia, 1977, 13, 111

${ }^{4}$ DeBoer, W, Collins, J, and Zimmet, P, Diabetologia, 1977, 13, 388
5 Prior, I A M, and Davidson, F, New Zealand Fournal of Medicine, 1966, 65, 375.

Bennett, P H, Burch, T A, and Miller, M, Lancet, 1971, 2, 125.

7 Reed, D, Labarthe, D, and Stallones, R, Arthritis and Rheumatism, 1972, 15,381 .

${ }^{8}$ Zimmet, P, Arblaster, M, and Thoma, K, Australian and New Zealand Fournal of Medicine. In press.

${ }^{9}$ Sobrinho-Simoes, M, fournal of Laboratory and Clinical Medicine, 1965, $65,665$.

${ }^{10}$ Kellgren, J H, Annals of the Rheumatic Diseases, 1964, 23, 109.

${ }_{11}$ O'Brien, W M, Burch, T A, and Bunim, J J, Annals of the Rheumatic Diseases, 1966, 25, 117.

${ }^{12}$ Mikkelsen, W M, Dodge, H J, and Valkenburg, H, American fournal of Medicine, 1965, 39, 242.

${ }^{13}$ Collins, J, et al, Proceedings of the 6th Asia and Oceania Congress of Endocrinology, Singapore, 1978. In press.

(Accepted 22 February 1978

\title{
Mechanism of action of insulin in diabetic patients : a dose-related effect on glucose production and utilisation
}

\author{
P M BROWN, C V TOMPKINS, S JUUL, P H SÖNKSEN
}

British Medical fournal, 1978, 1, 1239-1242

\section{Summary and conclusions}

Six insulin-requiring diabetics were studied after insulin had been withheld for 24 hours. On three separate occasions each received a two-hour infusion of insulin at a low dose $(2.6 \mathrm{U} / \mathrm{h})$ and a high dose $(10.6 \mathrm{U} / \mathrm{h})$ and an infusion of saline as control. The rates of production and utilisation of glucose were measured isotopically. The rate of fall of plasma glucose concentration was faster on the high-dose infusion of insulin than on the low, whereas the fall in plasma free fatty acids, glycerol, and keton bodies was the same on both insulin infusions. The mechanism whereby the two rates of insulin administration lowered plasma glucose concentration differed: during the low-dose infusion the decrease in the glucose concentration was produced entirely by a fall of hepatic glucose output, whereas during the high-dose insulin infusion the glucose concentration fell because both the rate of glucose production fell and the rate of glucose utilisation rose. In all experiments there was a direct relation between a fall in serum potassium concentration and the fall in plasma glucose concentration irrespective of the mechanism that reduced the glucose concentration.

These results indicate that in uncontrolled diabetics low-dose insulin infusions lower the blood glucose concentration entirely by reducing glucose production from the liver and that the effect of insulin on potassium transport is independent of its effect on glucose uptake.

\section{Introduction}

With the recent development of low-dose insulin infusions for treating diabetic ketoacidosis ${ }^{1}{ }^{2}$ we wondered whether insulin

Department of Medicine, St Thomas's Hospital Medical School, London SE1 7EH

P M BROWN, MRCP, research fellow

C V TOMPKINS, PHD, assistant lecturer

S JUUL, MSC, research assistant

$P$ H SÖNKSEN, FRCP, reader in medicine lowered blood glucose concentration by increasing glucose uptake by peripheral fat and muscle tissues or by reducing glucose production. Most studies that have shown an effect of insulin on increasing glucose transport into muscle have used high concentrations of insulin outside the physiological range. ${ }^{3}$ The effect of insulin in reducing hepatic glucose output was emphasised in the past ${ }^{5-}$ - but has been largely ignored recently. We used an isotope-turnover technique to measure the rates of production and utilisation of glucose during different rates of insulin infusion in hyperglycaemic diabetics treated with insulin. The rates of insulin infusion were chosen to produce plasma insulin concentrations in the low and high physiological range."

A fall in blood glucose concentration is known to be associated with a fall in serum potassium concentration and we therefore also studied changes in serum potassium during the insulin infusions.

\section{Patients and methods}

\section{PATIENT SELECTION AND PREPARATION}

Six insulin-dependent diabetic men aged 26 to 61 years were recruited from our diabetic clinic. The nature of the investigations was explained and their written consent to participate was obtained. Their diabetes had been treated with various types of short- and medium-acting insulin for a mean of $15 \cdot 2$ years (range $1 \cdot 5-37$ ). Their mean daily insulin requirement was 63 units (range 44-84). All were within $10 \%$ of ideal body weight. ${ }^{9}$

Each patient was studied on three separate occasions, at least one week apart. They received in random order either (a) a low-dose $(2.6 \mathrm{U} / \mathrm{h})$ or $(b)$ a high-dose $(10.6 \mathrm{U} / \mathrm{h})$ infusion of monocomponent porcine insulin or $(c)$ normal saline as placebo. Each patient, therefore, acted as his own control. Patients were studied as outpatients on the morning after an overnight fast. An appropriate dose of Actrapid monocomponent insulin (Novo) was substituted for the patients' usual insulin 24 hours before each study and insulin treatment was then withheld.

EXPERIMENTAL PROTOCOL

Cannulae were inserted into the antecubital veins of both arms using $1 \%$ procaine as local anaesthetic. One cannula was used for blood sampling and the other for infusions. An appropriate priming 
dose of $\mathrm{D}-\left[3-{ }^{3} \mathrm{H}\right]$ glucose was injected followed by a constant infusion at $0.165 \mathrm{LCi} / \mathrm{min}$ for the duration of the study. After 90 minutes equilibration a high-dose or low-dose infusion of monocomponent porcine insulin in isotonic saline with $1 \%$ albumin or an infusion of isotonic saline was administered for 120 minutes. After stopping the insulin the study was continued for another 60 minutes.

Samples of blood were taken every 10 minutes throughout the study. Plasma glucose was measured by a glucose oxidase method using a Beckman glucose analyser. Tritiated glucose in plasma was estimated using a liquid scintillation counter after precipitation of plasma proteins ${ }^{10}$ and lypophilisation. Rates of appearance (production) and disappearance (use) of glucose and metabolic clearance rates (MCR) for glucose were calculated using the method of Steele et al. ${ }^{11}$ The factor 0.65 was used as the rapidly exchangeable portion of the total glucose pool, which was assumed to be $22 \%$ of body weight. ${ }^{12}$ Blood samples were taken at the beginning of the insulin infusion, and every 60 minutes thereafter for measuring serum potassium concentrations (by flame photometry), blood ketone bodies, ${ }^{13}$ glycerol, ${ }^{14}$ and free fatty acids..$^{1.516}$

Timed 60-minute urine samples were collected during the hour immediately before the infusion, during the two hours of the infusion, and during the final hour of the study for measuring urinary glucose excretion. Standard statistical methods using paired $t$ tests were used when appropriate.

\section{Results}

\section{PLASMA GLUCOSE CONCENTRATION}

Fig 1 shows that the fasting plasma glucose concentration was raised in all the patients studied (range 10.2-29.7 mmol/1 (184-535 $\mathrm{mg} / 100 \mathrm{ml})$ ). Although there was a wide range of glucose concentrations among the patients, each patient had fairly constant values on the three occasions he was studied (greatest range $4.4 \mathrm{mmol} / 1(79 \mathrm{mg} / 100$ $\mathrm{ml})$ ).

During the control experiments the mean plasma glucose concentration fell by $1.5 \mathrm{mmol} / 1(27 \mathrm{mg} / 100 \mathrm{ml})$. During the two hours of insulin infusion the mean fall in plasma glucose concentration $(+\mathrm{SE}$ of mean) of $12 \cdot 6 \pm 0 \cdot 6 \mathrm{mmol} / 1(227 \pm 11 \mathrm{mg} / 100 \mathrm{ml})$ on the high-dose infusion was significantly greater than the mean fall of $8.4 \pm 0.9 \mathrm{mmol} / 1$ $(151 \pm 16 \mathrm{mg} / 100 \mathrm{ml})$ during the low-dose infusion $(\mathrm{P}<0 \cdot 01)$.

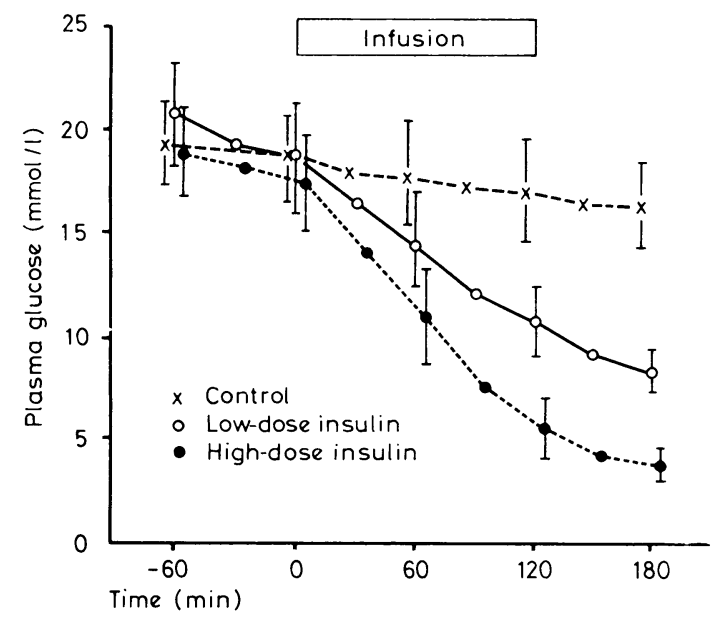

FIG 1 -Mean plasma glucose concentration \pm SE of mean for six patients during the saline infusion and low-dose and high-dose insulin infusions. All infusions were given from 0 to 120 minutes.

\section{GLUCOSE TURNOVER}

The average glucose production (rate of appearance) ( \pm SE of mean) during the preinfusion period was $20 \cdot 6 \pm 2.0 \mu \mathrm{mol} / \mathrm{kg} / \mathrm{min}(3.7 \pm 0.4$ $\mathrm{mg} / \mathrm{kg} / \mathrm{min}$ ). The rate of disappearance of glucose represents the sum of peripheral and visceral uptake and urinary loss of glucose. A measurement of metabolic uptake, which is the sum of peripheral and visceral uptake, was calculated by subtracting urinary glucose excretion from the rate of disappearance. In the preinfusion period the total rate of disappearance was slightly higher (mean $=23.3 \pm 2.4 \mu \mathrm{mol} / \mathrm{kg} /$ $\min (4 \cdot 2 \pm 0.43 \mathrm{mg} / \mathrm{kg} / \mathrm{min}))$ than the rate of appearance, accounting for the gradual reduction in plasma glucose concentration (fig 2).

The average resting metabolic uptake of glucose was $16 \cdot 3 \pm 1.6$ $\mu \mathrm{mol} / \mathrm{kg} / \mathrm{min}(3.0 \pm 0.29 \mathrm{mg} / \mathrm{kg} / \mathrm{min})$. During the control experiments there was a small and statistically non-significant fall in the rates of appearance and disappearance. There was no change in metabolic uptake or MCR throughout the control experiments.

The low-dose insulin infusion was associated with an immediate significant decrease of $37 \%$ in the rate of appearance compared with control $(\mathbf{P}<0.02)$. This fall continued throughout the infusion. There was no significant change in the rate of disappearance, metabolic

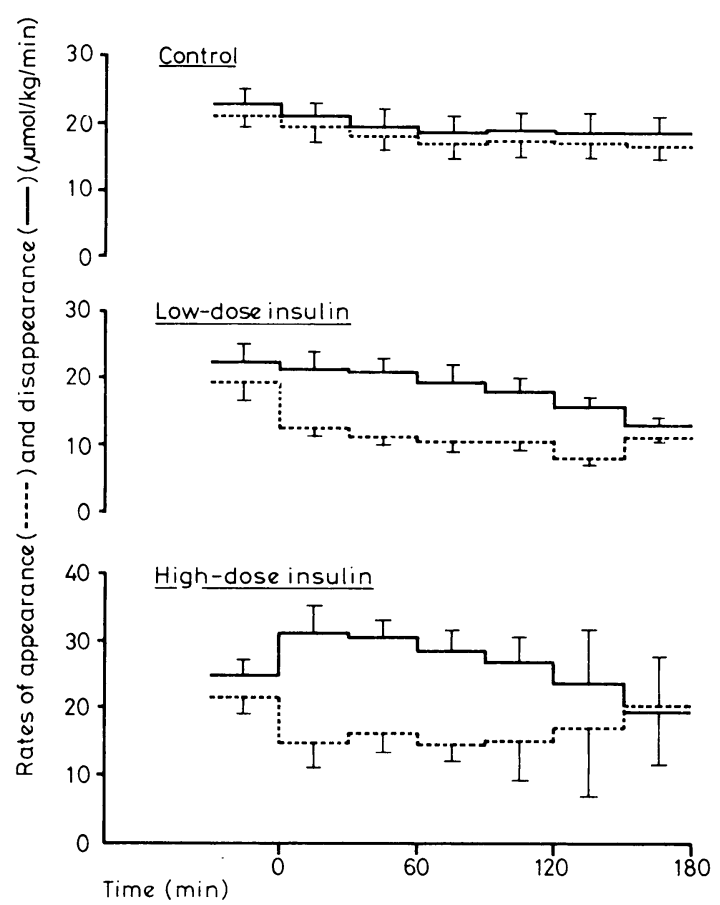

FIG 2-Mean rates of appearance and disappearance of glucose ( \pm SE of mean) for six patients during saline infusion and low-dose and high-dose insulin infusions.
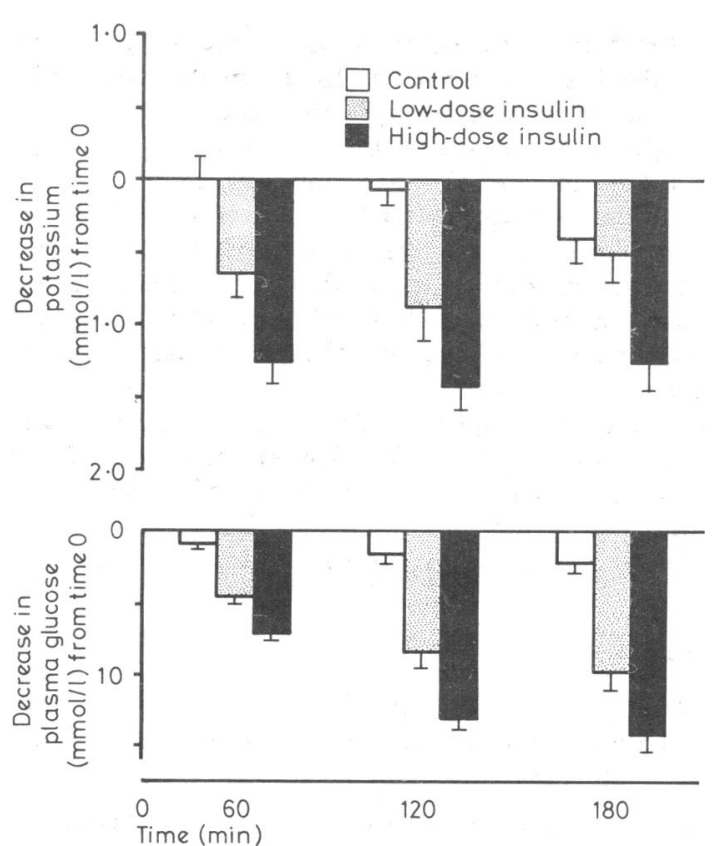

FIG 3-Decrease from preinfusion values in serum potassium concentrations and plasma glucose concentrations studied during saline infusion and lowdose and high-dose $(10.6 \mathrm{U} / \mathrm{h})$ insulin infusions. Results are shown at 60 minutes and 120 minutes during infusion and 60 minutes after stopping infusion. Values are means $\pm \mathrm{SE}$ of mean. 
uptake, or MCR during the low-dose insulin infusion compared with the control experiments.

During the first 30 minutes of the high-dose infusion there was a $31 \%$ decrease in the rate of appearance $(\mathrm{P}<0.05)$ and a $31 \%$ increase in the rate of disappearance $(P<0.02)$. Metabolic tissue uptake $(\mathrm{P}<0.01)$ and MCR $(\mathbf{P}<0.05)$ rose significantly.

\section{SERUM POTASSIUM CONCENTRATION}

There was no significant change in serum potassium concentration during the control experiment (fig 3). Both low- and high-dose insulin infusions were associated with a highly significant fall in serum potassium concentration after one and two hours of infusion compared with the control period $(P<0.001)$. When the results of all experiments were pooled (fig 4) there was a direct relation between the fall in serum potassium concentration and the fall in plasma glucose concentration $(r=0.77 ; P<0.001)$. The ratio of the fall of serum potassium concentration: fall of plasma glucose concentration was similar for high- and low-dose insulin infusions.

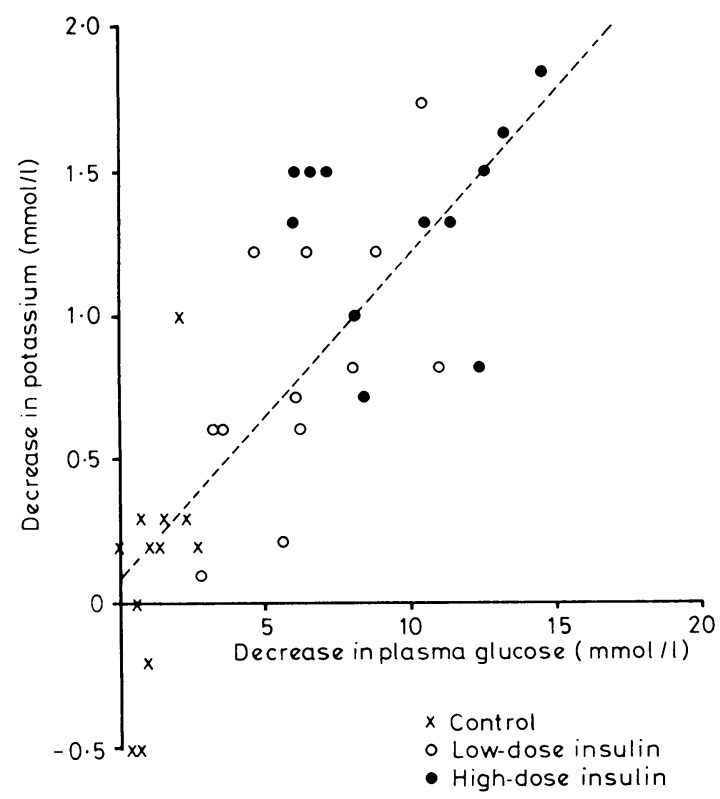

HIG 4-Relation between falls from preinfusion levels in serum potassium concentrations and plasma glucose concentrations during saline infusion and low-dose and high-dose $(10 \cdot 6 \mathrm{U} / \mathrm{h})$ insulin infusions for six diabetic patients $(\mathrm{r} .0 .77 ; \mathrm{P}<0.001)$. Values shown were measured at 60 and 120 minutes during infusion.

Concentrations (mmol $l$ ) of 3-hydroxybutyrate, acetoacetate, free fatty acids, and glycerol before and at 60 and 120 minutes during infusions of saline or low-dose or high-dose insulin in six diabetics. Results are expressed as means $\pm S E$ of mean for six patients

\begin{tabular}{|c|c|c|c|c|}
\hline \multirow{2}{*}{ Regimen } & & \multicolumn{3}{|c|}{ Time of infusion ( $\mathrm{min}$ ) } \\
\hline & & 0 & 60 & 120 \\
\hline \multicolumn{5}{|c|}{ 3-hydroxybutyrate } \\
\hline Placebo & . & $0.91: 0.43$ & $1 \cdot 04: 0.44$ & $1 \cdot 18: 0 \cdot 51$ \\
\hline Low-dose insulin & $\ldots$ & $0.82: 0.39$ & $0.38=0.28$ & $0 \cdot 18: 0 \cdot 14$ \\
\hline High-dose insulin & . & $0.92: 0.32$ & $0.41: 0.18$ & $0.11: 0.05$ \\
\hline \multicolumn{5}{|c|}{ Acetoacetate } \\
\hline Placebo & . & $0 \cdot 30: 0.09$ & $0.31: 0.09$ & $0.35: 0.09$ \\
\hline Low-dose insulin & $\therefore$ & $0 \cdot 28: 0 \cdot 10$ & $0 \cdot 18=0 \cdot 11$ & $0.11: 0.17$ \\
\hline High-dose insulin & . & $0.35: 0 \cdot 10$ & $0.23-0.09$ & $0.08: 0.02$ \\
\hline \multicolumn{5}{|c|}{ Free fatty acids } \\
\hline Placebo & .. & $0.84: 0.08$ & $0.88: 0 \cdot 10$ & $1 \cdot 22: 0 \cdot 18$ \\
\hline Low-dose insulin & . & $0.99: 0 \cdot 14$ & $0 \cdot 34 \cdot 0 \cdot 06$ & $0.28: 0.06$ \\
\hline High-dose insulin & $\cdot$ & $0.94: 0.16$ & $0.28 \div 0.04$ & $0.40 \div 0.08$ \\
\hline \multicolumn{5}{|c|}{ Glycerol } \\
\hline Placebo & . & $0.093 \div 0.012$ & $0 \cdot 102: 0.014$ & $0.092+0.017$ \\
\hline Low-dose insulin & . & $0.086 \div 0.012$ & $0.065: 0.008$ & $0.068: 0.010$ \\
\hline High-dose insulin & $\therefore$ & $0.123: 0.018$ & $0.071: 0.010$ & $0.111 \cdot 0.032$ \\
\hline
\end{tabular}

Conversion: SI to traditional units -3 -hydroxybutyrate $1 \mathrm{mmol} / 1=10.4 \mathrm{mg} / 100 \mathrm{ml}$ Acetoacetate: $1 \mathrm{mmol} 1 \approx 10.2 \mathrm{mg} 100 \mathrm{ml}$. Free fatty acids: $1 \mathrm{mmol} 1=25.6 \mathrm{mg} / 100$ Acetoacetate: $1 \mathrm{mmol} 1 \approx 10 \cdot 2 \mathrm{mg} 100 \mathrm{ml}$. Free fatty acids:
$\mathrm{ml}$ (as palmitic acid). Glycerol: $1 \mathrm{mmol} 1=9 \cdot 21 \mathrm{mg} 100 \mathrm{ml}$.

\section{METABOLITE AND FREE FATTY ACID CONCENTRATIONS}

The basal concentrations of 3-hydroxybutyrate, acetoacetate, free fatty acid, and glycerol were remarkably constant in the same patient at different times. The basal free fatty acid concentration was raised in only three of the six patients, but ketone body concentrations were raised in five.

The concentrations of 3-hydroxybutyrate, acetoacetate, and free fatty acids rose during the placebo experiments (see table). During both the low-dose and the high-dose insulin infusions mean concentrations of both ketone bodies fell significantly to within the normal range. There was no significant difference in concentrations of 3hydroxybutyrate and acetoacetate at 60 or 120 minutes between the low-dose infusion and the high-dose infusion. Similarly free fatty acid concentrations fell significantly $(\mathrm{P}<0.01)$ on both rates of insulin infusion and there was no difference in concentrations between low and high rates of infusion.

\section{Discussion}

Measurements of glucose turnover have been calculated by the method of Steele ${ }^{11}$ using $D-\left[3-{ }^{3} \mathrm{H}\right]$ glucose as a tracer. No correction for recycling of the tracer glucose was necessary as the tritium in the " 3 " position is irretrievably lost during glycolysis as tritiated water, which immediately equilibrates with body water. The glucose pool is not homogeneous and has different rates of equilibration. When a rapid change occurs in blood glucose concentration only a portion of the total pool participates in the change. In dogs this rapidly exchangeable portion has been calculated as being 0.65 of the total. ${ }^{12}$ This fraction may be different in human diabetics, so we also calculated the results using factors of 0.5 to 0.8 . Although the absolute rates of appearance and disappearance changed slightly, the direction of the changes was similar.

These results suggest that a low-dose infusion of insulin can lower plasma glucose entirely by reducing glucose production. Since at least $80^{\circ}{ }^{\circ}$ of glucose production in the fasting state is hepatic $^{17}$ this strongly suggests that low concentrations of insulin act primarily on the liver by reducing either glycogenolysis or gluconeogenesis or both. Only when insulin was administered at rates producing high physiological concentrations (about $\left.100 \mathrm{mU} / 1^{7}\right)$ did an increase in peripheral uptake of glucose by fat and muscle tissue contribute to lowering the plasma glucose concentration. These results confirm in man the results obtained by Issekutz on alloxan-diabetic dogs. ${ }^{1 *}$ We believe that the concentration-dependent effect of insulin on hepatic glucose production and uptake by peripheral tissues has important implications for insulin-treated diabetics.

In normal people endogenously secreted insulin is likely to affect mainly the liver because insulin secreted into the portal tract reaches the liver in concentrations many times greater than those reaching the periphery. ${ }^{19}$ The importance of the liver in normal glucose homoeostasis is emphasised by the results of the experiments of Felig et al, ${ }^{20}$ which showed that only $15^{\circ} \mathrm{o}$ of ingested glucose leaves the liver over three hours. In diabetics, who are insulin deficient, the restraining effect of insulin on hepatic glucose production is impaired and increased glucose production causes hyperglycaemia. The peripheral utilisation of glucose in diabetes is similar to that of normal subjects. ${ }^{21}$

When diabetic patients are treated with doses of subcutaneously administered insulin portal vein insulin concentrations are equal to or lower than those in the peripheral plasma. These relatively high peripheral plasma concentrations of insulin would be expected to have a greater effect on glucose uptake by peripheral tissues than similar amounts of endogenously secreted insulin. The inability to deliver insulin into the portal circulation of diabetic patients may contribute to the poor glucose control often achieved. There is some hope that new semi-synthetic insulins may have a greater hepatic than peripheral effect. ${ }^{22}$

The use of combined glucose and insulin regimens in treating severe hyperkalaemia has led to the widespread belief that potassium uptake and glucose uptake by tissues are linked. 
Our studies showed that serum potassium concentration fell in proportion to the fall in plasma glucose concentration. The fall in serum potassium concentration occurred irrespective of whether the fall in plasma glucose concentration was caused by inhibition of glucose output by the liver or by stimulation of peripheral glucose uptake. This suggests that insulin may affect potassium transport into cells independently of changes in glucose transport. This concept is not new-insulin increases potassium uptake into the isolated liver in a glucose-free medium, ${ }^{23}{ }^{24}$ and small doses of insulin cause potassium uptake but no glucose uptake in the human forearm. ${ }^{25}$ The changes in serum potassium concentration that we found differ from those reported by Schade and Eaton ${ }^{26}$ in dexamethasone-pretreated diabetics. In their patients the plasma potassium concentration had not changed after one hour of infusion of insulin at 0.01 and $0 \cdot 1 \mathrm{U} / \mathrm{kg} / \mathrm{h}$.

Our findings that concentrations of ketone bodies and free fatty acids are reduced by the low- and high-dose infusions of insulin suggest that these metabolic pathways are highly sensitive and that the plasma insulin concentration achieved with the low-dose infusion is sufficient to inhibit free fatty acid release and ketogenesis. Schade and Eaton ${ }^{26}$ also reported that ketone bodies and free fatty acids were maximally reduced by an insulin infusion of $0 \cdot 1 \mathrm{U} / \mathrm{kg} / \mathrm{h}$. Low-dose insulin regimens will probably be effective in correcting the ketonaemia and acidaemia in uncontrolled diabetes and also cause less profound changes in serum potassium concentration.

The dose-dependent effect of insulin on the liver and peripheral tissues that we have shown in man emphasises the importance of steady-state plasma insulin concentrations in experiments designed to investigate the mechanism of action of insulin. Our results also emphasise the importance of the effect of insulin on glucose production in diabetes, which has been largely ignored.

We thank Dr R R McSwiney for estimating the serum potassium concentrations and Sister $\mathrm{S}$ Judd for invaluable help in conducting the studies. This investigation was supported in part by the St Thomas's Hospital Research (Endowments) Committee and the British Diabetic Association.

\section{References}

${ }^{1}$ Sönksen, P H, et al, Lancet, 1972, 2, 155

2 Page, M Mc B, et al, British Medical fournal, 1974, 2, 687.

${ }^{3}$ Daniel, P M, Love, E R, and Pratt, O E, fournal of Physiology, 1975, 247, 273.

${ }^{4}$ Henderson, M J, Wrenshall, G A, and Odeuse, P, Canadian fournal of Biochemistry, 1955, 33, 926

${ }^{5}$ Soskin, S, et al, American fournal of Physiology, 1938, 124, 558.

${ }^{6}$ Madison, L L, et al, Metabolism, 1959, 8, 469.

' Bondy, P, et al, fournal of Clinical Investigation, 1949, 28, 1126

* Sönksen, P H, Tompkins, C V, and Strivastava, M C, Clinical Science and Molecular Medicine, 1973, 45, 633.

${ }^{9}$ UDGP Report, Diabetes, 1970, 19, 747.

${ }^{10}$ Somogyi, M, fournal of Biological Chemistry, 1945, 160, 69.

11 Steele, R, et al, American fournal of Physiology, 1956, 187, 15.

${ }^{12}$ Cowan, J S, and Hetenyi, G, jun, Metabolism, 1971, 20, 360.

13 Hohorst, H J, Kreutz, F H, and Bücher, T, Biochemische Zeitschrift, $1959,332,18$

${ }^{14}$ Williamson, D H, Mellanby, P, and Krebs, H A, Biochemical fournal, $1962,82,90$.

${ }^{15}$ Kreutz, F H, Klinische Wochenschrift, 1962, 40, 362.

${ }^{16}$ Carruthers, M, and Young, D A, Clinica Chimica Acta, 1973, 49, 341.

7 Bergman, E N, Brockman, R P, and Daufman, C F, Federation Proceedings, 1974, 33, 1849.

${ }^{18}$ Issekutz, B, et al, Diabetologia, 1974, 10, 323.

${ }^{19}$ Blackard, W G, and Nelson, N C, Diabetes, 1970, 19, 302.

${ }^{20}$ Felig, P, Wahren, J, and Hendler, R, Diabetes, 1975, 24, 468

${ }^{21}$ Forbath, W, and Hetenyi, G, jun, Diabetes, 1966, 15, 778.

2 Tompkins, $\mathrm{C} \mathrm{V}$ and Sönksen, $\mathrm{P} \mathrm{H}$ Clinical Science and Molecular Medicine, 1976, 50, 31P.

${ }^{3}$ Mortimore, G E, American fournal of Physiology, 1961, 200, 1315.

24 Burton, S D, Mondon, C E, and Ishida, T, American fournal of Physiology, 1967, 212, 261.

${ }^{25}$ Zierler, K L, and Rabinowitz, D, fournal of Clinical Investigation, 1964, 43, 950 .

${ }^{26}$ Schade, D S, and Eaton, P R, Journal of Clinical Endocrinology and Metabolism, 1977, 44, 1038 .

(Accepted 3 March 1978)

\title{
Cimetidine for recurrent ulcer after vagotomy or gastrectomy: a randomised controlled trial
}

\author{
TERENCE KENNEDY, ANNE SPENCER
}

British Medical fournal, 1978, 1, 1242-1243

\section{Summary and conclusions}

In a randomised controlled trial cimetidine $1 \mathrm{~g}$ daily for six weeks was compared with placebo in the treatment of recurrent ulcers after gastrectomy or vagotomy for duodenal ulcer. Healing, assessed endoscopically, was seen in seven out of 12 patients given cimetidine and in five out of 12 controls. Four of the controls whose ulcers did not heal were subsequently treated with cimetidine, and in two the ulcers healed after six weeks. Pain recorded

Royal Victoria Hospital, Belfast BT12 6BA, N Ireland TERENCE KENNEDY, Ms, FRCS, consultant surgeon ANNE SPENCER, $\mathrm{MB}, \mathrm{BCH}$, research assistant

by the patient and consumption of alkalis were each slightly but not significantly less in the cimetidinetreated patients.

When cimetidine is to be used for recurrent ulceration 0 probably the dosage and duration of treatment should be increased.

\section{Introduction}

Cimetidine reduces gastric acidity and promotes healing of $\frac{\mathbb{Q}}{\mathscr{Q}}$ duodenal and gastric ulcers. When ulceration recurs after $\bar{O}$ gastrectomy or vagotomy the usual cause is inadequate reduction of acidity; thus cimetidine might also be expected to promote healing of these ulcers. Delle Fave $e t a l^{1}$ found healing at two months in nine out of 10 patients with recurrent ulcer after $\frac{\bar{a}}{2}$ gastrectomy; Hoare et al ${ }^{2}$ were successful at six weeks in 17 out of 20 patients; and Wastell et $a l^{3}$ found healing in four out of eight patients at the end of six weeks.

All these were open trials without controls. We have con- 